\title{
Strong $\sigma$-hole activation on icosahedral carborane derivatives for a directional halide recognition
}

\author{
Maxime Beau, ${ }^{+[a]}$ Sunhee Lee, ${ }^{+[b]}$ Sooyeon Kim, ${ }^{[b]}$ Won-Sik Han, ${ }^{*[b]}$ Olivier Jeannin, ${ }^{[a]}$ Marc \\ Fourmigué, ${ }^{*[a]}$ Emmanuel Aubert, ${ }^{[c]}$ Enrique Espinosa, ${ }^{[c]}$ and le-Rang Jeon*[a]
}

[a] M. Beau, Dr. O. Jeannin, Dr. M. Fourmigué, Dr. I.-R. Jeon

Univ Rennes, CNRS, ISCR (Institut des Sciences Chimiques de Rennes), Campus de Beaulieu, 35000 Rennes, France.

E-mail: marc.fourmigue@univ-rennes1.fr, ie-rang.jeon@univ-rennes1.fr

[b] S. Lee, S. Kim, Prof. Dr. W.-S. Han

Department of Chemistry, Seoul Women's University, Seoul 01797, Republic of Korea.

[c] Dr. E. Aubert, Prof. Dr. E. Espinosa

Laboratoire CRM2, UMR CNRS 7036, Institut Jean Barriol, Université de Lorraine, BP 70239, 54506 Vandoeuvre-lès-Nancy, France.

†These authors contributed equally to this work.

Supporting information, including experimental details on the syntheses and physical characterization of 1-3, 1-Br, 2-CI, 3-I, and 3-Br, details on ESP calculations, molecular structures, ${ }^{1} \mathrm{H},{ }^{13} \mathrm{C}$, DEPT-135 spectra of $\mathbf{1}$ and 2, crystallographic tables, additional ESP maps, and cif files for 1, 2, 1-Br, 2-CI, 3-I, 3-Br, and the ORCID identification number(s) for the author(s) of this article can be found under: http://doi.org/XXXXX.

\begin{abstract}
Crystal engineering based on $\sigma$-hole interactions is an emerging approach for realization of new materials with higher complexity. Neutral inorganic clusters derived from 1,2-dicarba-closododecaborane, substituted with -SeMe, $-\mathrm{TeMe}$, and -I moieties on both skeletal carbon vertices are experimentally demonstrated here as outstanding chalcogen- and halogen-bond donors. In particular, these new molecules strongly interact with halide anions in the solidstate. The halide ions are coordinated by one or two donor groups ( $\mu_{1-}$ and $\mu_{2}$-coordinations), to stabilize a discrete monomer or dimer motifs to 1D supramolecular zig-zag chains. Crucially, the observed chalcogen bond and halogen bond interactions feature remarkably short distances and strong directionality. Electrostatic potential calculations further demonstrate the efficiency of the carborane derivatives, with $V_{s, \max }$ being similar or even superior to that of reference organic halogen bond donors such as iodopentafluorobenzene.
\end{abstract}

\section{Introduction}

Increasing demand in materials with higher complexity and more elaborate functions is driving research in the field of crystal engineering in conjunction with supramolecular chemistry. ${ }^{1}$ Indeed, $\sigma$-hole interactions have been emerged during the last two decades as an appealing chemical tool to control intermolecular interactions, with their implications in crystal engineering, catalysis, functional materials, and biochemistry. ${ }^{2-8}$ By far the most studied one is halogen bonding (XB), ${ }^{2}$ which is defined as a net attractive interaction between an electrophilic region ( $\sigma$-hole) associated with a halogen atom in a molecular entity and a nucleophile. Study of such noncovalent interactions has recently evolved to the investigation of heavier Group 14, 15, and 16 elements. ${ }^{9}$ For example, the electrophilic regions of a chalcogen atom can be also activated to give rise $\sigma$-hole interactions, so called chalcogen bonding ( $\mathrm{ChB}) .^{5}$ This phenomenon has been studied in the solid-state structures largely with amphoteric molecules, serving for both $\mathrm{ChB}$ donor and ChB acceptor, such as benzoselenadiazoles, telluradiazoles, iso-tellurazole $\mathrm{N}$-oxides, and selenophthalic anhydride. ${ }^{10-15}$ Moreover, molecules involving activated chalcogen atoms have been used to chelate a Lewis base, in the field of organocatalysis or anion recognition. ${ }^{16-20}$ Despite those observations and discoveries, harnessing the $\mathrm{ChB}$ for crystal engineering remains challenging due to the presence of two $\sigma$-holes that can significantly deviate from the $\mathrm{C}-\mathrm{Ch}$ bond axis, ${ }^{21,22}$ in contrast to monotopic and directional XB.

In targeting efficient $\mathrm{ChB}$ donor building blocks for crystal engineering strategies, the employment of one strong electronwithdrawing group acting on a chalcogen can unbalance the electrophilic character of its $\sigma$-holes and therefore drive a preferred anchoring site in their competition for intermolecular interactions, raising the potential directionality along one of them. For example, organic selenocyanates have been found recently to interact not only by themselves through efficient $\mathrm{Se} \cdots \mathrm{N} \equiv \mathrm{C} \mathrm{ChB}$ but also with di- and multi-topic Lewis bases. ${ }^{23}$ To further strengthen $\sigma$-hole interactions and control the bulkiness of the building block, we have turned our attention to an interesting class of exceptionally stable and electronically tunable clusters, icosahedral carboranes. ${ }^{24}$ Owing to its $3 \mathrm{D}$ aromaticity, ${ }^{25}$ the substituents on the more electronegative carbon vertices of the carborane experience strong electron withdrawing effects. ${ }^{24,26}$ Theoretical studies and a few structural analyses on carborane and heteroborane cages themselves have been recently performed to understand the electron deficient regions. ${ }^{27}$ However, a systematic study of C-substituted carboranes as directional $\mathrm{ChB}$ and $\mathrm{XB}$ donors and their implementation in crystal engineering has yet to be explored.

To this end, we considered neutral 1,2-dicarba-closododecaborane (o-carborane, 1,2- $\mathrm{C}_{2} \mathrm{~B}_{10} \mathrm{H}_{12}$ ) with -SeMe, -TeMe, and $-\mathrm{I}$ substituents on both carbon atoms as potentially highly efficient ditopic $\mathrm{ChB}$ and XB donor building blocks. Moreover, substituents with lone pairs on the carbon atoms of $O$-carborane are known to contribute their electron density to the cluster by filling the anti-bonding orbital that is located mainly between the two carbon centers. ${ }^{28}$ This effect should further strengthen the electropositive character of the chalcogen atoms. Herein, we report their synthesis and formation of cocrystal salts from the 
association of these carboranes with halide salts, demonstrating their ability to efficiently coordinate halide anions through strong and directional $\sigma$-hole interactions.

\section{Results and Discussion}

Synthesis of the $\mathrm{ChB}$ donor molecules was effected through reaction of $1,2-\mathrm{C}_{2} \mathrm{~B}_{10} \mathrm{H}_{12}$ with 2 equivalent of $n$-BuLi followed by the addition of selenium and tellurium, respectively (Scheme 1). Subsequent methylation with Mel yielded yellow oils. Column chromatography on the crude material and the sublimation under reduced pressure yielded white needle-shaped crystals of 1,2$(\mathrm{SeMe})_{2} \mathrm{C}_{2} \mathrm{~B}_{10} \mathrm{H}_{10}$ (1) and yellow needle-shaped 1,2$(\mathrm{TeMe})_{2} \mathrm{C}_{2} \mathrm{~B}_{10} \mathrm{H}_{10}$ (2) in 68 and $5 \%$ yield respectively. For the preparation of the $\mathrm{XB}$ donor molecule, iodine was added after the lithiation of $1,2-\mathrm{C}_{2} \mathrm{~B}_{10} \mathrm{H}_{12}$, following a previously reported procedure. ${ }^{29}$

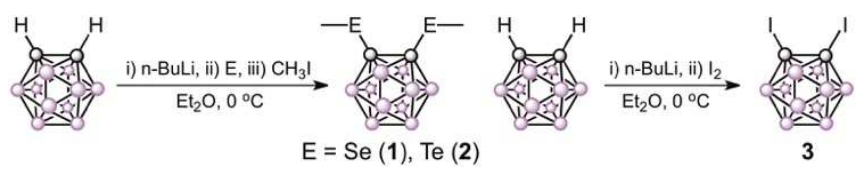

Scheme 1. Synthetic routes to $1-3$, gray and pink spheres represent $C$, and $B$ atoms, respectively.

$\mathbf{1}$ and $\mathbf{2}$ are isostructural and crystallize in the orthorhombic system, space group Fdd2 with carborane molecule located on the 2-fold axis. Two methyl groups are out of the mean-plane defined by Se-C-C-Se and trans to each other with respect to the $\mathrm{C}-\mathrm{C}$ bond of the carborane (Figure S1). The Se atom in $\mathbf{1}$ is not engaged in any short contact. On the contrary, as shown in Figure S2, the Te atom in $\mathbf{2}$ is engaged in Te $\cdots \mathrm{H}-\mathrm{B}$ interactions with distances $(3.151 \AA)$ that are marginally shorter than the contact distance $(3.26 \AA)$ with a modest directionality $\left(\angle \mathrm{C}_{\text {carborane }}-\right.$ $\left.\mathrm{Te} \cdot \mathrm{H} 160^{\circ}\right)$. Recently, $\mathrm{Br}$ atom substituted on the carbon atom of the o-carborane was also reported to be engaged in weak halogen bonding interactions with $-\mathrm{BH}$ of the carborane cage. ${ }^{27 \mathrm{~d}}$ However, the observed Te... H-B interaction in $\mathbf{2}$ is rather described as a weak hydrogen bond, regarding the geometry of the contact angle and the decreased nucleophilic power of the Te due to the polarization. The $\mathrm{C}-\mathrm{C}$ distances in $\mathbf{1}$ and $\mathbf{2}$ amount 1.751(6) and 1.745(6) $\AA$, respectively, which are significantly longer than the one in the unsubstituted $1,2-\mathrm{C}_{2} \mathrm{~B}_{10} \mathrm{H}_{12}(1.624 \AA)$. The observed $\mathrm{C}-\mathrm{C}$ elongation supports the electron back donation

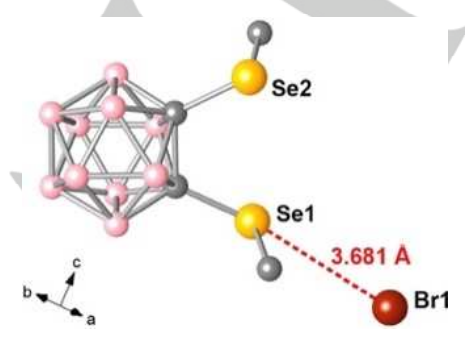

Figure 1. X-ray crystal structure of $[(1) \mathrm{Br}]^{-}$in $1-\mathrm{Br}$, collected at $\mathrm{T}=298 \mathrm{~K}$. Yellow, red, gray, and pink spheres represent $\mathrm{Se}, \mathrm{Br}, \mathrm{C}$, and $\mathrm{B}$ atoms, respectively; $\mathrm{H}$ atoms and $\mathrm{Bu}_{4} \mathrm{~N}^{+}$cation are omitted for clarity. The red dotted lines indicate the chalcogen bond interaction. towards the cluster antibonding orbital, ${ }^{28}$ which likely further contribute to the activation of the $\sigma$-hole in Se and Te.

The cocrystallization of $\mathbf{1}, \mathbf{2}$, and $\mathbf{3}$ with $\mathrm{n}$ tetrabutylammonium halide salts in ethanol afforded single crystals of $\left(\mathrm{Bu}_{4} \mathrm{~N}\right)[(\mathbf{1}) \mathrm{Br}](1-\mathrm{Br}),\left(\mathrm{Bu}_{4} \mathrm{~N}\right)[(2) \mathrm{Cl}](2-\mathrm{Cl}),\left(\mathrm{Bu}_{4} \mathrm{~N}\right)[(3) \mathrm{l}]$ $(3-\mathrm{I})$, and $\left(\mathrm{Bu}_{4} \mathrm{~N}\right)[(3) \mathrm{Br}](3-\mathrm{Br})$.

The salt $1-\mathrm{Br}$ crystallizes in the monoclinic system, space group $P 2_{1} / c$, with molecule $1, \mathrm{Bu}_{4} \mathrm{~N}^{+}$cation and $\mathrm{Br}^{-}$anion in general positions. The two methyl groups are in trans configuration, as observed in the structure of the donor itself. As shown in Figure 1, the bromide anion is chalcogen bonded to one of the Se atoms, leaving the other selenium atom in 1 free. The Se $\cdots \mathrm{Br}$ distance is $3.681 \AA$, that is shorter than the contact distance $(3.86 \AA)$ determined as the sum of van der Waals radius of Se $(1.98 \AA)$ and bromide ionic radius (1.96 $\AA$ ), giving a reduction ratio $(\mathrm{RR})$ of 0.95 . Despite modest strength, the Se atom of the carborane is engaged in a highly directional interaction with the $\mathrm{C}_{\text {carborane }}-\mathrm{Se} \cdots \mathrm{Br}$ angle of $173^{\circ}$.

With the molecule 2 involving a heavier chalcogen Te atom, a chloride salt 2-Cl was obtained. While 1-2 are isostructural, their halide salts crystallize in different space groups with distinctive coordination environment for each. 2-Cl crystallizes in the triclinic system, space group $P 1$. There are four independent moieties of each component, carborane, $\mathrm{Bu}_{4} \mathrm{~N}^{+}$cation and $\mathrm{Cl}^{-}$anion. The two methyl groups of all carborane molecules in $\mathbf{2}-\mathbf{C l}$ are either in cis configurations or in a configuration with one methyl group roughly on the Te-C-C-Te mean-plane and the other out of the plane (Figure 2).

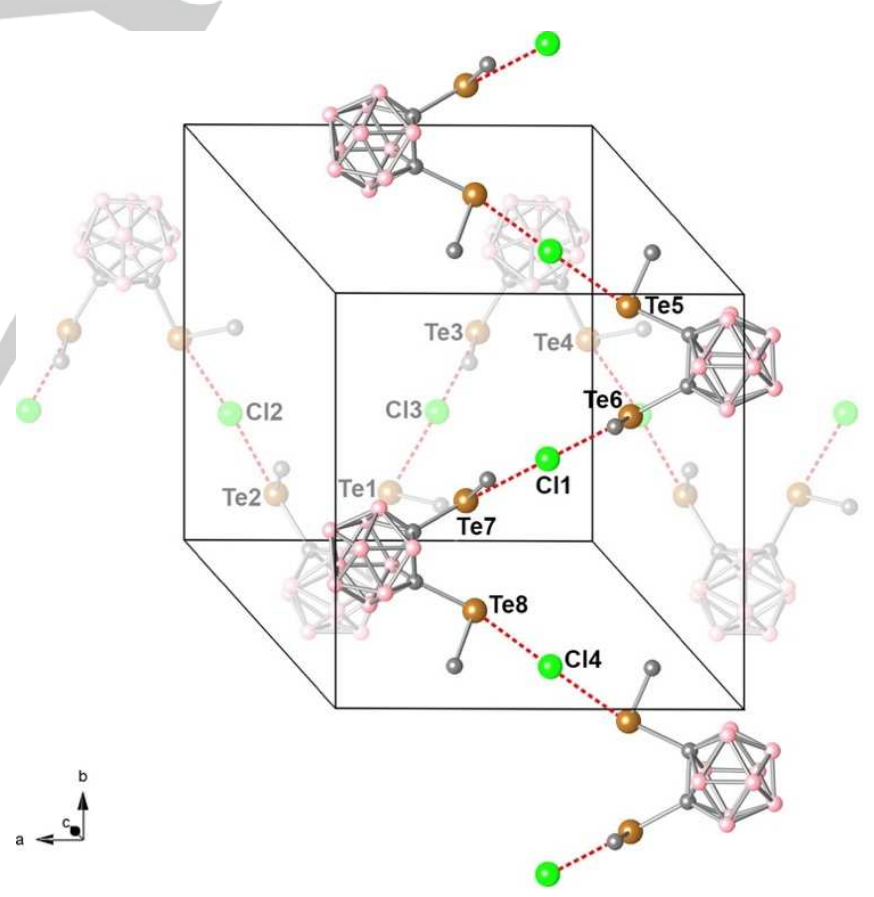

Figure 2. Detail of two independent chalcogen bonding chains running along the $\mathrm{a}$ and $\mathrm{b}$ directions, respectively, in 2-Cl. Light brown, green, gray, and pink spheres represent $\mathrm{Te}, \mathrm{Cl}, \mathrm{C}$, and $\mathrm{B}$ atoms, respectively; $\mathrm{H}$ atoms and $\mathrm{Bu}_{4} \mathrm{~N}^{+}$ cation are omitted for clarity. The red dotted lines indicate the chalcogen bond interaction. 
Table 1. Chalcogen bond characteristics in 2-Cl.

\begin{tabular}{cccccc}
\hline & $\mathrm{Te} \cdots \mathrm{Cl}[\AA ̊]$ & $\mathrm{C}-\mathrm{Te} \cdots \mathrm{Cl}\left[{ }^{\circ}\right]$ & & $\mathrm{Te} \cdots \mathrm{Cl}[\AA \AA$ & $\mathrm{C}-\mathrm{Te} \cdots \mathrm{Cl}\left[{ }^{\circ}\right]$ \\
\hline $\mathrm{Te} 1$ & $3.154(8)$ & $177.3(6)$ & $\mathrm{Te} 5$ & $3.143(8)$ & $170.6(5)$ \\
$\mathrm{Te} 2$ & $3.087(8)$ & $175.7(6)$ & $\mathrm{Te} 6$ & $3.112(7)$ & $178.1(5)$ \\
$\mathrm{Te} 3$ & $3.064(8)$ & $170.9(5)$ & $\mathrm{Te} 7$ & $3.120(7)$ & $173.1(4)$ \\
$\mathrm{Te} 4$ & $3.155(10)$ & $171.4(5)$ & $\mathrm{Te} 8$ & $3.139(9)$ & $169.1(5)$ \\
\hline
\end{tabular}

All chloride ions are coordinated by two Te atoms from the adjacent molecules, giving a $\mu_{2}$ coordination. The Te... Cl...Te coordination deviates from linearity, with angles between 151 and $167^{\circ}$. Unlike the singly activated $\mathrm{Se}$ in $\mathbf{1 - B r}$, all Te atoms in $\mathbf{2 - C l}$ are activated to be engaged in the chalcogen bonding interactions. The interaction distances and angles vary (Table 1) with the shortest distance being $\mathrm{Te} 3 \cdots \mathrm{Cl} 3=3.064 \AA(\mathrm{RR}=0.79)$ and the greatest directionality being $\angle \mathrm{C} 10-\mathrm{Te} 6 \cdots \mathrm{Cl} 1=178^{\circ}$, representing one of the strongest Te-based chalcogen bonded crystalline materials. ${ }^{6,7}$ To the best of our knowledge, this is a rare example of structurally characterized halide coordination through a Te-based chalcogen bonding, ${ }^{30}$ although those in solution has been studied recently. ${ }^{10 e, 17,18}$

Since the activated $\sigma$-hole is located on the prolongation of the $\mathrm{C}_{\text {carborane }}-\mathrm{Te}$ bond, not along the $\mathrm{C}_{\mathrm{Me}}-\mathrm{Te}$ bond, each carborane is interacting with two different chloride anions rather than chelating one chloride anion. Consequently, zig-zag 1D extended supramolecular networks are stabilized through chalcogen bonding interactions where each chain comprises two independent carborane molecules and two chloride anions (Figure 2). The resulting two chains are orthogonal to each other, one chain runs along the a axis, and the other runs along the $b$ axis.

With the diiodinated carborane 3 , crystals of an iodide salt 3-I and a bromide salt 3-Br were exclusively obtained. 3-I crystallizes in the monoclinic system, space group $P 2_{1} / n$ with carborane molecule, $\mathrm{Bu}_{4} \mathrm{~N}^{+}$cation and $\mathrm{I}^{-}$anion in general positions. The iodide anion is two-coordinated with an $|\ldots|-\ldots \mid$ angle of $139^{\circ}$. The $\sigma$-hole of both iodine atoms of the carborane are activated to form an 1D supramolecular network, as observed in 2-Cl (Figure 3). The $\left.\left.\right|^{\prime} \cdot\right|^{-}$distances amount 3.336(2) $(R R=$ $0.80)$ and $3.377(1)(R R=0.81) \AA$, respectively, with the $C-|\cdots|^{-}$ angles of 175 and $171^{\circ}$.

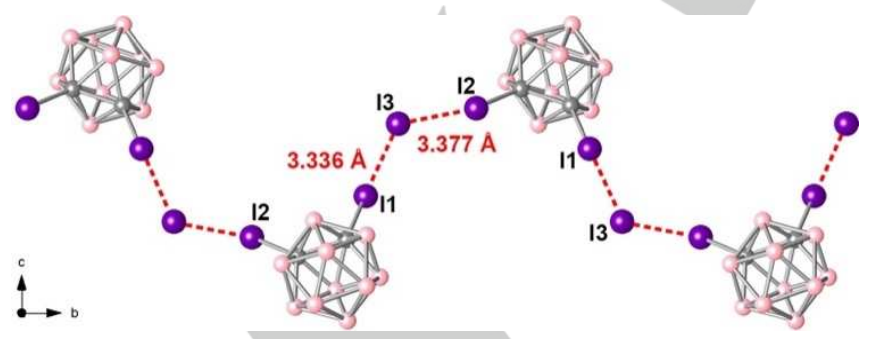

Figure 3. Detail of halogen-bonded $1 \mathrm{D}$ network running along the $b$ direction in 3-I. Purple, gray, and pink spheres represent I, C, and B atoms, respectively; $\mathrm{H}$ atoms and $\mathrm{Bu}_{4} \mathrm{~N}^{+}$cation are omitted for clarity. The red dotted lines indicate the halogen bond interaction.

By changing the iodide to the smaller bromide anion, crystals of $3-\mathbf{B r}$ were obtained. They crystallize in the triclinic system, space group $P-1$. 3, $\mathrm{Bu}_{4} \mathrm{~N}^{+}$cation and $\mathrm{Br}^{-}$anion are in general positions. The bromide ion is interacting with two iodine atoms of symmetry related carborane molecules with an $\left|\cdots \mathrm{Br}^{-} \cdots\right|$ angle $\left(116^{\circ}\right)$. The smallest coordination angle of the halide anion in $\mathbf{3 - B r}$ compared to other salts in the series likely stabilizes the formation of a dimer instead of chains (Figure 4). As a consequence, both iodine atoms are engaged in highly directional halogen bonding interactions $\left(\angle \mathrm{C}-\mathrm{I} \cdots \mathrm{Br}=174\right.$ and $\left.177^{\circ}\right)$ with I..Br distances being 3.136(3) $(\mathrm{RR}=0.80)$ and 3.123(4) $(\mathrm{RR}=$ 0.79) $\AA$.

The halogen bonding interactions observed here represent one of the shortest $\left.|\cdots|\right|^{-}$and $\mid \cdots \mathrm{Br}^{-}$distances reported so far. In particular, there exist only 12 structures revealing the shorter I...Br distances than $3.123 \AA(R R=0.77-0.79)$ based on the CCDC database search. All of them, except one, are ionic molecules, where the positive charge of the imidazolium strongly activates the iodine. There is one neutral molecule, that is 1,4diiodotetrafluorobenzene (GIXFUO, RR $=0.79$ ), ${ }^{31}$ however, the coordination number of the bromide is 1 . Indeed, larger coordination numbers (for $n<6$ ), is known to deactivate the Lewis base character of the halide anions, and therefore favor larger distances. Taken together, the activation of iodine $\sigma$-hole by the neutral inorganic carborane moiety is shown to be highly effective, being similar or even superior to strong electron-withdrawing organic groups.

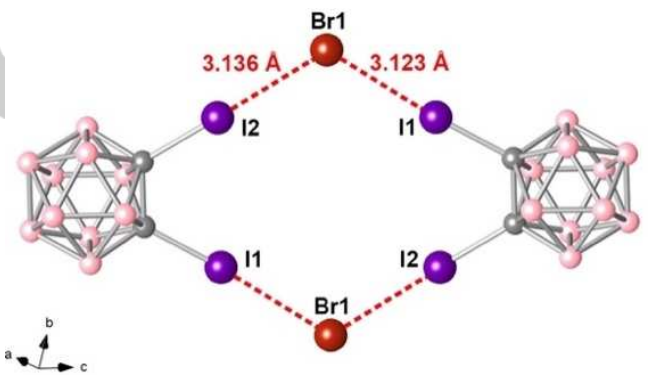

Figure 4. Detail of halogen-bonded dimeric molecular unit in 3-Br. Purple, red, gray, and pink spheres represent $\mathrm{I}, \mathrm{Br}, \mathrm{C}$, and $\mathrm{B}$ atoms, respectively; $\mathrm{H}$ atoms and $\mathrm{Bu}_{4} \mathrm{~N}^{+}$cation are omitted for clarity. The red dotted lines indicate the halogen bond interaction.

To gain further insight into the observed $\sigma$-hole interactions, we have performed electrostatic potential (ESP) calculations on 1-3. As shown in Figure 5, a strongly electron deficient region is generated for each chalcogen atom in $\mathbf{1}(\mathrm{Se})$ and $\mathbf{2}(\mathrm{Te})$ in the prolongation of the $\mathrm{C}_{\text {carborane }}-\mathrm{Ch}$ bond, with much larger $\mathrm{V}_{\mathrm{s} \text {, max }}$ value for $2(34.4 \mathrm{kcal} / \mathrm{mol})$ than the one for $1(27.5 \mathrm{kcal} / \mathrm{mol})$. A second $\sigma$-hole also exists on Se and Te with a less pronounced $\mathrm{V}_{\mathrm{s}, \max }$ values (12.8 and $19.9 \mathrm{kcal} / \mathrm{mol}$ for 1 and 2, respectively) owing to the electron donating power of the methyl group (Figures S3 and S4). The $V_{s, \max }$ value in $\mathbf{1}$ is comparable with some recently reported organodiselenide compounds with strong electron withdrawing substituents, such as bis(pnitrophenyl)diselenide $(22.5$ and $17.3 \mathrm{kcal} / \mathrm{mol}$ for Se-Se and CSe directions, respectively) and dicyanodiselenide (37.3 and 40.0 $\mathrm{kcal} / \mathrm{mol}$ for Se-Se and C-Se directions, respectively). ${ }^{32}$ The 3 also shows a $\sigma$-hole on each iodine in the prolongation of the $\mathrm{C}_{\text {carborane}}-\mathrm{I}$ bond, with a $\mathrm{V}_{\mathrm{s} \text {, max }}$ value of $36.4 \mathrm{kcal} / \mathrm{mol}$. Note that this value is slightly lower than the one previously calculated by another group $\left(\mathrm{V}_{\mathrm{s}, \max }=41.3 \mathrm{kcal} / \mathrm{mol}\right)$ using different calculation 
method. ${ }^{27 a}$ More interestingly, the $\mathrm{V}_{\mathrm{s} \text {, max }}$ values in 1-3 can be also compared with those found, for example, in prototypical organic halogen bond donor molecules such as 1,4diiodotetrafluorobenzene (32.2 $\mathrm{kcal} / \mathrm{mol}) \quad$ and iodopentafluorobenzene $(33.0 \mathrm{kcal} / \mathrm{mol})$ in the same calculation conditions. This comparison further highlights that the $\sigma$-hole activation through carborane reveals a strength comparable or superior to well-established halogen bond donors. (a)

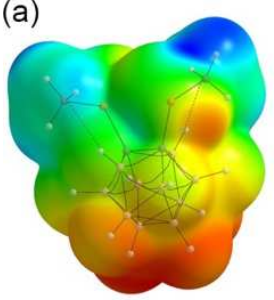

(b)

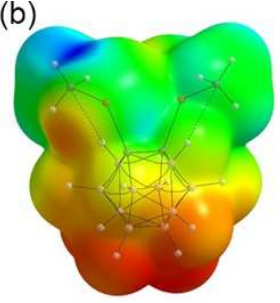

(c)

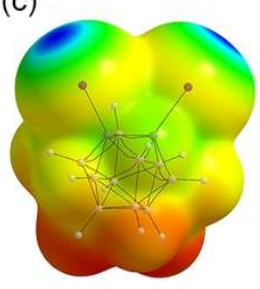

Figure 5. Computed electrostatic potential of $\mathbf{1}$ (a), 2 (b), and $\mathbf{3}$ (c) on the 0.001 electron/bohr ${ }^{3}$ contour of the electronic density. The extrema values Vs, max of the electropositive (blue) area are 27.5, 34.4, and $36.4 \mathrm{kcal} / \mathrm{mol}$ for 1, 2, and $\mathbf{3}$, respectively. Potential scale ranges from -15.7 (red) to $36.4 \mathrm{kcal} / \mathrm{mol}$ (blue).

\section{Conclusion}

In summary, the foregoing results demonstrate that 1,2-dicarbacloso-dodecaborane, with -SeMe, -TeMe, and -I substituents on both carbon vertices can indeed act as strong $\mathrm{ChB}$ and $\mathrm{XB}$ donors and interact with halide anions in the solid-state to form isolated molecular units or extended supramolecular chains through $\mu_{1}$ and $\mu_{2}$-halide structures. The previous theoretical prediction ${ }^{27 a}$ made on the $-\mathrm{I}$ analogue as a good halogen bond donor is experimentally proved here. Furthermore, this strategy is successfully extended towards chalcogen bond donors, -SeMe and -TeMe analogues. Notably, the observed chalcogen- and halogen-bond metrics indicate strong and directional interactions, with a reduction ratio down to 0.79 , for $\mathrm{Te} \cdots \mathrm{Cl}^{-}$and $\mathrm{I} \cdots \mathrm{Br}$, one of the smallest known for any $\sigma$-hole interaction stabilized by a neutral donor molecule. Such a high efficiency is further illustrated by the electrostatic potential calculation, revealing a profound electron-deficient zone. We also prove the inorganic carborane can excellently enhance one of two sigma-holes on chalcogen atoms, to provide directionality and predictability, which are crucial parameters for crystal engineering. Work is underway to investigate the recognition ability of the carborane derivatives towards different types of Lewis bases.

\section{Acknowledgements}

This research was supported by the French National Research Agency Grant, ANR 17-ERC3-0003, the Campus France PHC STAR 41595RK and the National Research Foundation of Korea (NRF-2018K1A3A1A21043478). Authors thank CDIFX (Rennes) for the use of X-ray diffractometer. We are grateful to the Région Bretagne for a PhD grant of M.B. The EXPLOR mesocentre is thanked for providing access to computing facility (project 2019CPMXX0984/wbg13).
Keywords: Carborane $\bullet$ Chalcogen bonding • Crystal engineering $\cdot$ Halogen bonding $\cdot$ Sigma-hole interaction

[1] G. R. Desiraju, J. J. Vittal, A. Ramanan, Crystal Engineering, World Scientific Publishing, Singapore, 2011; C. R. Laramy, M. N. O’Brien, C. A. Mirkin, Nat. Rev. Mater. 2019, 4, 201; R. R. Knowles, E. N. Jacobsen, PNAS 2010, 107, 20678; O. R. Evans, W. Lin, Acc. Chem. Res. 2002, 35, 511; K. Biradha, R. Santra, Chem. Soc. Rev. 2013, 42, 950; A. S. Tayi, A. Kaeser, M. Matsumoto, T. Aida, S. I. Stupp, Nat. Chem. 2015, 7, 281; E. Mattia, S. Otto, Nat. Nano. 2015, 10, 111; N. Blagden, M. de Matas, P. T. Gavan, P. York, Adv. Drug Deliv. Rev. 2007, 59, 617; C. Wang, H. Dong, L. Jiang, W. Hu, Chem. Soc. Rev. 2018, 47, 422.

[2] G. Cavallo, P. Metrangolo, R. Milani, T. Pilati, A. Priimagi, G. Resnati, G. Terraneo, Chem. Rev. 2016, 116, 2478.

[3] L. C. Gilday, S. W. Robinson, T. A. Barendt, M. J. Langton, B. R. Mullaney, P. D. Beer, Chem. Rev. 2015, 115, 7118.

[4] M. S. Taylor, Coord. Chem. Rev. 2020, 413, 213270.

[5] C. B. Aekeroy, D. L. Bryce, G. R. Desiraju, A. Frontera, A. C. Legon, F. Nicotra, K. Rissanen, S. Scheiner, G. Terraneo, P. Metrangolo, G. Resnati, Pure Appl. Chem. 2019, 91, 1889; S. Benz, A.I. PobladorBahamonde, N. Low-Ders, S. Matile, Angew. Chem. Int. Ed. 2018, 57, 5408; Angew. Chem. 2018, 130, 5506.

[6] P. Scilabra, G. Terraneo, G. Resnati, Acc. Chem. Res. 2019, 52, 1313.

[7] N. Biot, D. Bonifazi, Coord. Chem. Rev. 2020, 413, 213243.

[8] M. Fourmigué, A. Dhaka, Coord. Chem. Rev. 2020, 403, 213084.

[9] G. Cavallo, P. Metrangolo, T. Pilati, G. Resnati, G. Terraneo, Cryst. Growth Des. 2014, 14, 2697.

[10] a) A. F. Cozzolino, P. J. W. Elder, I. Vargas-Baca, Coord. Chem. Rev. 2011, 255, 1426; b) A. F. Cozzolino, J. F. Britten, I. Vargas-Baca, Cryst. Growth Des. 2006, 6, 181; c) A. F. Cozzolino, I. Vargas-Baca, S. Mansour, A. H. Mahmoudkhani, J. Am. Chem. Soc. 2005, 127, 3184; d) A.F. Cozzolino, Q. Yang, I. Vargas-Baca, Cryst. Growth Des. 2010, 10, 4959; e) G. E. Garrett, G. L. Gibson, R. N. Straus, D. S. Seferos, M. S. Taylor, J. Am. Chem. Soc. 2015, 137, 4126.

[11] L.-J. Riwar, N. Trapp, K. Root, R. Zenobi, F. Diederich, Angew. Chem. Int. Ed. 2018, 57, 17259; Angew. Chem. 2018, 130, 17506.

[12] A. Kremer, A. Fermi, N. Biot, J. Wouters, D. Bonifazi, Chem. -Eur. J. 2016, 22, 5665.

[13] a) P. C. Ho, P. Szydlowski, J. Sinclair, P. J. W. Elder, J. Kübel, C. Gendy, L. M. Lee, H. Jenkins, J. F. Britten, D. R. Morim, I. Vargas-Baca, Nat. Commun. 2016, 7, 11299 ; b) P.C. Ho, J. Rafique, J. Lee, L.M. Lee, H.A. Jenkins, J.F. Britten, A.L. Braga, I. Vargas-Baca, Dalton Trans. 2017, 46, 6570 .

[14] M. Brezgunova, J. Lieffrig, E. Aubert, S. Dahaoui, P. Fertey, S. Lebègue, J. Angyan, M. Fourmigué, E. Espinosa, Cryst. Gowth Des. 2013, 13, 3283.

[15] K. Eichstaedt, A. Wasilewska, B. Wicher, M. Gdaniec, T. Połoński, Cryst. Growth Des. 2016, 16, 1282; N. Biot, D. Bonifazi, Chem. Eur. J. 2020, 26, 2904.

[16] a) P. Wonner, L. Vogel, M. Düser, L. Gomes, F. Kniep, B. Mallick, D.B. Werz, S. M. Huber, Angew. Chem. Int. Ed. 2017, 56, 12009; Angew. Chem. 2017, 129, 12172; b) P. Wonner, L. Vogel, F. Kniep, S. M. Huber, Chem. Eur. J. 2017, 23, 16972; c) P. Wonner, A. Dreger, L. Vogel, E. Engelage, S.M. Huber, Angew. Chem. Int. Ed. 2019, 58, 16923; Angew. Chem. 2019, 131, 17079; d) P. Wonner, T. Steinke, L. Vogel, S.M. Huber, Chem. Eur. J. 2020, 26, 1258.

[17] a) J. Y. C. Lim, I. Marques, A. L. Thompson, K. E. Christensen, V. Félix, P. D. Beer, J. Am. Chem. Soc. 2017, 139, 3122; b) J. Y. C. Lim, J. Y. Liew, P. D. Beer, Chem. Eur. J. 2018, 24, 14560; c) A. Borissov, I. Marques, J. Y. C. Lim, V. Félix, M. D. Smith, P. D. Beer, J. Am. Chem. Soc. 2019, 141, 4119; d) T. Bunchuay, A. Docker, U. Eiamprasert, P. Surawatanawong, A. Brown, P. Beer, Angew. Chem. Int. Ed. 2020, 59, 12007; Angew. Chem. 2020, 132, 12105.

[18] G. E. Garrett, E. I. Carrera, D. S. Seferos, M. S. Taylor, Chem. Commun. 2016, 52, 9881.

[19] N. A. Semenov, D. E. Gorbunov, M. V. Shakhova, G. E. Salnikov, I. Y. Bagryanskaya, V. V. Korolev, J. Beckmann, N. P. Gritsan, A. V. Zibarev, Chem. Eur. J. 2018, 24, 12983. 
[20] a) S. Benz, M. Macchione, Q. Verolet, J. Mareda, N. Sakai, S. Matile, J. Am. Chem. Soc. 2016, 138, 9093; b) K. Strakova, L. Assies, A. Goujon, F. Piazzolla, H.V. Humeniuk, S. Matile, Chem. Rev. 2019, 119, 10977; c) L. M. Lee, M. Tsemperouli, A. I. Poblador-Bahamonde, S. Benz, N Sakai, K. Sugihara, S. Matile, J. Am. Chem. Soc. 2019, 141, 810.

[21] W. Wang, B. Ji, Y. Zhang, J. Phys. Chem. A 2009, 113, 8132; E. Alikhani, F. Fuster, B. Madebene, G. J. Grabowski, Phys. Chem. Chem. Phys. 2014, 16, 2430; D. J. Pascoe, K. B. Lin, S. L. Cockroft, J. Am. Chem. Soc. 2017, 139, 15160.

[22] P. Politzer, J. S. Murray, T. Clark, G. Resnati, Phys. Chem. Chem. Phys. 2017, 19, 32166 .

[23] H.-T. Huynh, O. Jeannin, M. Fourmigué, Chem. Commun. 2017, 53 , 8467; O. Jeannin, H.-T. Huynh, A. M. S. Riel, M. Fourmigué, New. J. Chem. 2018, 42, 10502; V. Kumar, C. Leroy, D. L. Bryce, CrystEngComm 2018, 20, 6406; A. M. S. Riel, H.-T. Huynh, O. Jeannin, O. Berryman, M. Fourmigué, Cryst. Growth Des. 2019, 19, 1418; A. M. S. Riel, O. Jeannin, O. Berryman, M. Fourmigué, Acta Cryst. 2019, B75, 34.

[24] R. N. Grimes, Carboranes, Elservier, 2011.

[25] J. Aihara, J. Am. Chem. Soc. 1978, 100, 3339 ; P. von R. Schleyer, K. Najafian, Inorg. Chem. 1998, 37, 3454; Z. F. Chen, R. King, Chem. Rev. 2005, 105, 3613; J. Poater, M. Solà, C. Viñas, F. Teixidor, Angew. Chem Int. Ed. 2014, 53, 12191; Angew. Chem. 2014, 126, 12387.

[26] F. Teixidor, R. Núñez, C. Viñas, R. Sillanpää, R. Kivekäs, Angew. Chem. Int. Ed. 2000, 39, 4290; Angew. Chem. 2000, 112, 4460; F. Teixidor, G. Barberà, A. Vaca, R. Kivekäs, R. Sillanpää, J. Oliva, C. Viñas, J. Am. Chem. Soc. 2005, 127, 10158; A. M. Spokoyny, C. W. Machan, D. J. Clingerman, M. S. Rosen, M. J. Wiester, R. D. Kennedy, C. L. Stern, A A. Sarjeant, C. A. Mirkin, Nat. Chem. 2011, 3, 590.

[27] a) R. Lo, J. Fanfrlík, M. Lepšík, P. Hobza, Phys. Chem. Chem. Phys. 2015, 17, 20814; b) J. Fanfrlík, A. Přáda, Z. Padělková, A. Pecina, J. Macháček, M. Lepšík, J. Holub, A. Růžička, D. Hnyk, P. Hobza, Angew. Chem. Int. Ed. 2014, 53, 10139; Angew. Chem. 2014, 126, 10303; c) A. Pecina, M. Lepšík, D. Hnyk, P. Hobza, J. Fanfrlík, J. Phys. Chem. A 2015 119, 1388; d) J. Fanfrlík, J. Holub, Z. Růžičová, J. Řezáč, P. D. Lane, D.
A. Wann, D. Hnyk, A. Růžička, P. Hobza, ChemPhysChem 2016, 17, 3373.

[28] J. M. Oliva, N. L. Allan, P. v. R. Schleyer, C. Viñas, F. Teixidor, J. Am. Chem. Soc. 2005, 127, 13538.

[29] a) G. Barberà, A. Vaca, F. Teixidor, R. Sillanpää, R. Kivekäs, C. Viñas, Inorg. Chem. 2008, 47, 7309; b) H. Ni, Z. Qiu, Z. Xie, Angew. Chem. Int. Ed. 2017, 56, 712; Angew. Chem. 2017, 129, 730.

[30] a) V. Kumar, Y. Xu, D. L. Bryce, Chem. Eur. J. 2020, 26, 3275; b) CCDC (CSD version 5.41, November 2019) based search shows 12 structures, albeit not being studied in the frame of chalcogen bond interaction, where Te-containing molecules are all ionic. (REF: ATIDIQ, DIYDUL, GEGHUW, KIXCEZ, OCURIN, RADMUH, RADNES, RADNOC, WOHGIM, XEMMEJ, YETVID, YETVOJ); D. B. Werz, R. Gleiter, F Rominger, Organometallics, 2015, 34, 5341; J. Beckmann, P. Finke, S. Heitz, M. Hesse, Eur. J. Inorg. Chem. 2008, 1921; J. Konu, T. Chivers, H. M. Tuononen, Chem. Commun. 2006, 1634; H. Fleischer, D. Schollmeyer, Inorg. Chem. 2002, 41, 10678; T. G. Do, E. Hupf, A. Nordheider, E. Lork, A. M. Z. Slawin, S. G. Makarov, S. Yu. Ketkov, S. Mebs, J. D. Woollins, J. Beckmann, Organmetallics 2015, 34, 53415360; P. Arsenyan, S. Lapcinska, A. Ivanova, J. Vasiljeva, Eur. J. Inorg. Chem. 2019, 4951; A. V. Borisov, Zh. V. Matsulevich, B. K. Osmanov, G. N. Borisova, V. I. Naumov, G. Z. Mamedova, A. M. Magerramov, V. N. Khrustalev, V. V. Kachala, Russ. Chem. Bull. 2012, 89; K. Konu, T. Chivers, H. M. Tuononen, Inorg. Chem. 2006, 45, 10678.

[31] CCDC (CSD version 5.41, November 2019) based search; J. Grebe, G. Geiseler, K. Harms, K. Dehnicke, Z. Naturforsch. B 1999, 54, 7.

[32] P. Scilabra, J. S. Murray, G. Terraneo, G. Resnati, Cryst. Growth Des. 2019, 19, 1149; the calculation method in the reference is different with the one used in this paper, and the values reported here are those obtained using our calculation method. Note that the these values show marginal differences (up to ca. $2 \%$ ) with the reported ones. Details and comparisons with the reported data are described in the supporting information. 


\section{Entry for the Table of Contents}
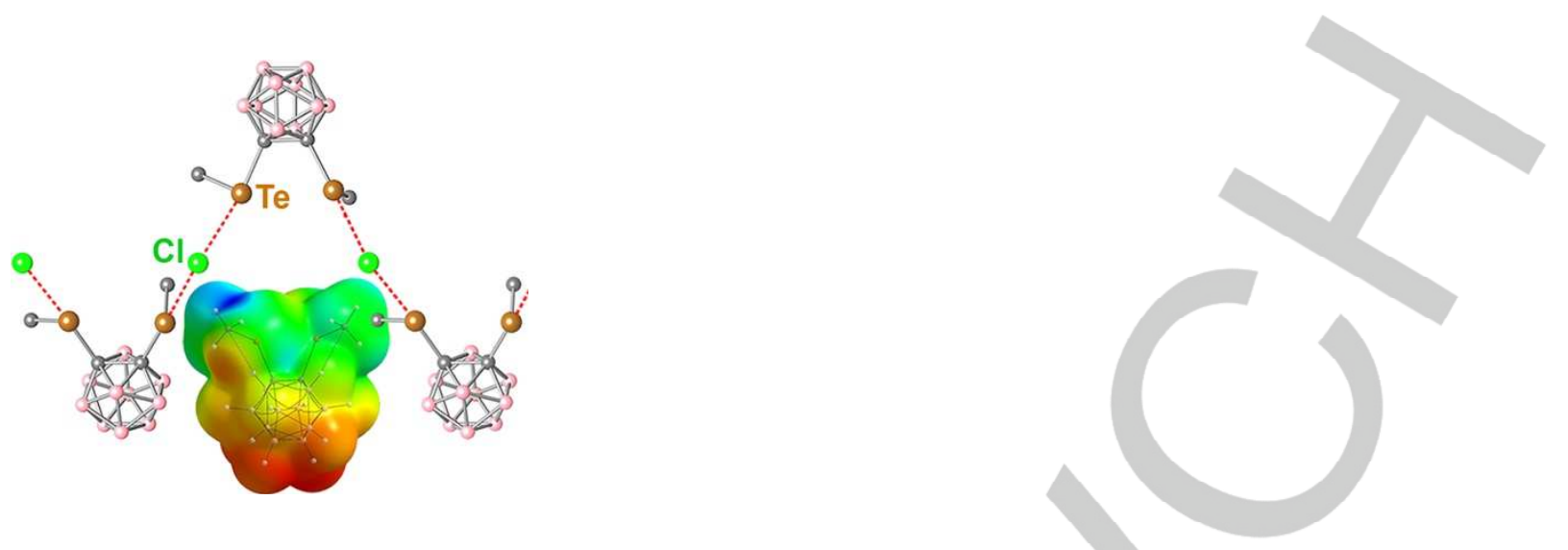

Carborane activates Se, Te, and I : Substituted carborane with -SeMe, -TeMe, and -I groups on the skeletal carbon vertices are demonstrated here as outstanding chalcogen bond $(\mathrm{ChB})$ and halogen bond $(\mathrm{XB})$ donors to recognize halide anions. Moreover, the observed interactions are found to be remarkably efficient with short distances and strong directionality. Theoretical calculations further validate the presence of a deep $\sigma$-hole on Se, Te, and I. 